\title{
Self-reported Continuous Positive Airway Pressure Device Compliance of Patients with Obstructive Sleep Apnoea Syndrome
}

\author{
Fatih Uzer, Ummuhan Okur, Aykut Cilli \\ Department of Respiratory Disease, Akdeniz University, Antalya, Turkey
}

\section{Abstract}

Introduction: Patients with obstructive sleep apnoea syndrome (OSAS) are often prescribed the use of continuous positive airway pressure (CPAP) devices to overcome obstruction during sleep. We aimed at assessing the adherence rates to CPAP therapy in two clinical subtypes of OSAS. Patients and Methods: Patients diagnosed with positional or rapid eye movement related OSAS using polysomnography were included. Patients were contacted by telephone calls to collect data. Inclusion criteria were age $>18$ years, a total apnea-hypopnea index (AHI) $>5$, and a physician recommendation to initiate therapy with a CPAP device. Patients were excluded if they had known neurological disorders, were unwilling to answer all questions and had no recommendation to use CPAP therapy. Results: A total of 286 patients, 99 females (34.6\%) and 187 males (65.4\%), with a mean age of $56.5 \pm 11.3$ years were included. There were 134 (46.9\%) CPAP users and 152 (53.1\%) CPAP nonusers. Reasons for not using the CPAP device included unwillingness to use the device ( $n=73,48 \%)$, reduced patient comfort due to noise, hose, or air pressure $(n=31,20.3 \%)$, reimbursement problems $(n=38,25 \%)$, and reasons such as recovery or operation $(n=10,6.5 \%)$. Age, duration of use/months, number of nights per week during which the device was used and the mean number of hours per night were not significantly different between OSAS types $(P>0.05)$, while the mean AHI and body mass index were significantly different between OSAS types $(P<0.05)$. Conclusion: A significant proportion of OSAS patients do not use CPAP devices due to various reasons. Adherence to CPAP therapy was not significantly different between groups.

Keywords: Adherence, compliance, continuous positive airway pressure, obstructive sleep apnea syndrome, positional, rapid eye movement

\section{INTRODUCTION}

Obstructive sleep apnea syndrome (OSAS) is a disorder characterized by partial or complete obstruction of the upper respiratory airways during sleep. ${ }^{[1-3]}$ Due to the recent recognition of different clinical characteristics and particularly due to the advances in positive airway pressure treatments, different clinical types of OSAS have been defined, with corresponding therapeutic approaches. The current understanding of OSAS does not involve a single clinical entity. However, until recently, the diagnosis of OSAS was only based on apnea-hypopnea index (AHI) without considering the association with position and sleep stages, and this diagnosis can be referred to as the classical OSAS.

One particular aspect of the polysomnography (PSG) results of OSAS patients is the occurrence of OSAS in relation to the

\begin{tabular}{|l|l|}
\hline \multicolumn{3}{|c|}{ Access this article online } \\
\hline Quick Response Code: & Website: \\
\hline & www.ijrc.in \\
\hline & \\
\hline
\end{tabular}

sleep stage rapid eye movement (REM) and/or position (supine) of the patient. Positional OSAS is defined as a supine AHI at least two times the nonsupine $\mathrm{AHI}$ in a patient diagnosed with OSAS (total AHI >5), on the condition that the nonsupine AHI is within the normal range $(<5)$. REM-related OSAS is defined as a REM-AHI at least two times the non-REM-AHI in a patient diagnosed with OSAS (total AHI $>5$ ), on the condition that non-REM-AHI is within the normal range $(<5){ }^{[1-3]}$ The current fundamental therapeutic approach for OSAS involves

Address for correspondence: Dr. Fatih Uzer, Department of Chest Diseases, Akdeniz University, Antalya, Turkey. E-mail: uzerfatih@gmail.com

This is an open access journal, and articles are distributed under the terms of the Creative Commons Attribution-NonCommercial-ShareAlike 4.0 License, which allows others to remix, tweak, and build upon the work non-commercially, as long as appropriate credit is given and the new creations are licensed under the identical terms.

For reprints contact:WKHLRPMedknow_reprints@wolterskluwer.com

How to cite this article: Uzer F, Okur U, Cilli A. Self-reported continuous positive airway pressure device compliance of patients with obstructive sleep apnoea syndrome. Indian J Respir Care 2021;10:221-5.

Received: $23-12-2020$

Revised: 03-02-2021

Accepted: 08-04-2021 Published: 14-06-2021 
continuous positive airway pressure (CPAP) treatment. CPAP has been reported to improve sleep quality, reduce daytime sleepiness, and increase quality of life in many studies. ${ }^{[4]}$ On the other hand, despite the efficacy of CPAP treatment in alleviating obstruction in the upper airways and despite advances in device technology (less noise, softer mask, smaller device), adherence to CPAP therapy remains limited. In many studies, the long-term adherence rates to CPAP in those patients who require it have been reported to be only in the range of $30 \%-60 \%{ }^{[5-7]}$ In this study, we aimed at assessing the adherence rates to CPAP therapy in two clinical subtypes of OSAS, i.e., REM-related OSAS and positional OSAS.

\section{Patients and Methods}

Patients diagnosed with positional or REM-related OSAS using PSG at the Sleep Laboratory of the Department of Pulmonology, Akdeniz University between January 1, 2014, and December 31, 2017 were included. Patients were contacted by telephone calls to collect demographic data and to asked questions about their adherence to CPAP therapy. Inclusion criteria were age over 18 years, a total $\mathrm{AHI}>5$, and a physician recommendation to initiate therapy with a CPAP device. Patients were excluded if they had known neurological disorders, who were unwilling to answer all questions, and had no physician recommendation for CPAP therapy. The main signals recorded during PSG included the following: Electroencephalography allowing the identification of sleep state, conscious state, and sleep stage; electrooculogram and submental electromyogram; electrocardiogram for cardiac rhythm; airflow for respiratory functions; thoracoabdominal effort belts; and oximetry. Polysomnographic evaluations of patients were performed by a specialist doctor who is an expert in the field of sleep. PSG results were manually scored according to AASM criteria for each patient. ${ }^{[8]}$

Apnea was defined as a $\geq 10 \mathrm{~s}$ interruption in the airflow as documented by the oro-nasal airflow-meter, while hypopnea was defined as the $\geq 50 \%$ reduction for $\geq 10 \mathrm{~s}$ in oro-nasal airflow-meter measurements together with a $\geq 4 \%$ reduction in oxygen saturation and occurrence of arousals. The total apnea and hypopnea episodes detected during a 1-h sleep period was defined as the AHI. Positional OSAS is defined as a supine-AHI at least two times the nonsupine AHI in a patient diagnosed with OSAS (total AHI $>5$ ), on the condition that the nonsupine AHI is within the normal range $(<5)$. REM-related OSAS is defined as a REM-AHI at least two times the non-REM-AHI in a patient diagnosed with OSAS (total AHI $>5$ ), on the condition that non-REM-AHI is within the normal range $(<5)$.

CPAP pressures of patients were adjusted and continued according to the recommendations of the specialist doctor who is following the patient. This doctor was an expert on sleep. All patients were using fixed-pressure CPAP device. During fixed-CPAP titration, the optimal CPAP pressure was determined manually to abolish apnea, hypopnea, oxygen desaturation, and any obvious inspiratory flow limitation without arousing the patient. Patients who used CPAP for a minimum of $4 \mathrm{~h} /$ day for at least $70 \%$ of total follow-up days were defined as compliant.

The study protocol was approved by the Ethics Committee, Akdeniz University (approved on October 10, 2018, under number 2018/715).

In all, there were 286 study participants. The data were analyzed using IBM SPSS Statistics 23.0 (IBM Corp. Released 2015. IBM SPSS Statistics for Windows, Version 23.0. Armonk, NY, USA: IBM Corp) software pack. For the assessment of study data, the numerical variables were evaluated using parametric tests, as for $\mathrm{n} \rightarrow \infty$, the distribution of the mean of the samples approaches that of the normal distribution according to the law of large numbers. Frequency distribution was provided for categorical variables, while descriptive statistics (mean, standard deviation, minimum, maximum) were provided for numerical variables. Statistical comparison of clinical data between two groups consisted of unpaired $t$-tests, whereas the Chi-square/Fisher's exact tests were used for categorical variables. ROC curve analyses were also performed to estimate cut-off values for the number of nights per week and the number of hours per night during which the patients were required to use CPAP to feel recovered, and the results were presented in tables.

\section{RESULTS}

A total of 652 patients were screened, and 366 of these were excluded due to a variety of reasons (no physician recommendation for CPAP therapy [300], no telephone contact [32], unwillingness for study participation[34] etc.). Thus, 286 patients, 99 female (34.6\%) and 185 male $(65.4 \%)$, with a mean age of $56.5 \pm 11.3$ years were included [Table 1]. Of these, $21.0 \%(n=60)$ and $79 \%(n=226)$ had REM-related OSAS and positional OSAS, respectively. There were 134 (46.9\%) CPAP users and 152 (53.1\%) CPAP nonusers [Figure 1]. It was found that all patients used oronasal masks and all of them had a heated-humidifier.

The reasons for not using CPAP device included unwillingness to use the device ( $n=73,48 \%$ ), reduced patient comfort due to noise, hose, or air pressure $(n=31,20.3 \%)$, reimbursement problems $(n=38,25 \%)$, and other reasons such as recovery or operation $(n=10,6.5 \%)$. Of the CPAP users, $88.0 \%(n=117)$ reported improvement, while $11.3 \%(n=15)$ reported no change, and $0.8 \%(n=1)$ reported worsening. Independent sample $t$-test showed no significant differences in terms of age, duration of CPAP use (months), weekly number of nights with CPAP use between two OSAS types $(P>0.05)$. However, a significant difference was noted with regard to mean AHI and body mass index $(\mathrm{BMI})(P<0.05)$. In both groups, the average CPAP usage duration during night were $6 \mathrm{~h}$ and over. This result shows that both groups were compliant with the CPAP device. However, no statistically significant difference was determined between the two groups $(P=0.113)$. Accordingly, patients with positional OSAS had significantly higher mean 
Uzer, et al.: Compliance to CPAP in OSAS

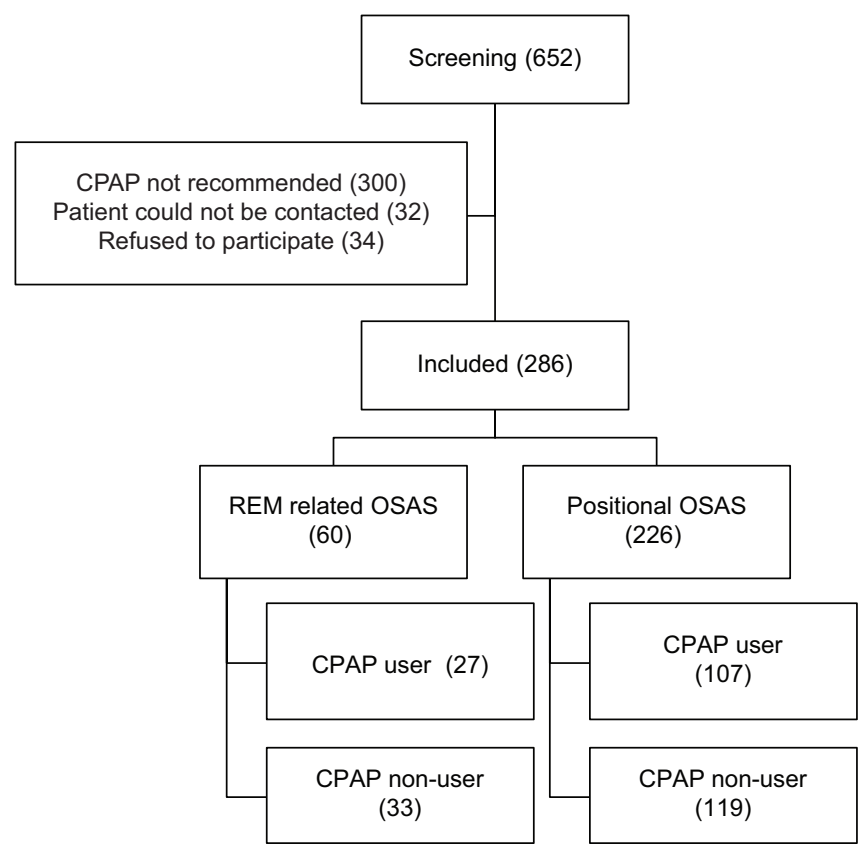

Figure 1: Patient disposition

\begin{tabular}{lc}
\hline \multicolumn{2}{l}{ Table 1: Basic demographic and clinical characteristics of } \\
the patients \\
\hline Feature & Data \\
\hline Age (years), mean \pm SD & $56.5 \pm 11.3$ \\
Sex, $n(\%)$ & $187(65.4)$ \\
Male & $99(34.6)$ \\
Female & $31.4 \pm 5.3$ \\
BMI (kg/m $\left.{ }^{2}\right)$, mean \pm SD & $22.6 \pm 13.7$ \\
AHI (event/hours), mean \pm SD & \\
Comorbidities, $n(\%)$ & $150(52.4)$ \\
Yes & $136(47.6)$ \\
No & $30.6 \pm 17.3$ \\
Mean duration of CPAP use (months) \pm SD & $6.1 \pm 1.7$ \\
Mean number of nights with CPAP use (weekly) \pm SD & $6.8 \pm 1.8$ \\
\hline Mean number of hours with CPAP use (per night) \pm SD & \\
\hline BMI: Body mass index, AHI: Apnea-hypopnea index, SD: Standard \\
deviation, CPAP: Continuous positive airway pressure
\end{tabular}

AHI scores than REM-related OSAS patients, and patients with REM-related OSAS had significantly higher mean BMI as compared to positional OSAS patients [Table 2]. The ROC curves indicated that patients needed to use CPAP for an average of 3.5 days/week (sensitivity: 0.71 , specificity: 0.93 ) and $6.5 \mathrm{~h}$ per night (sensitivity: 0.64 , specificity: 0.78 ) to feel recovered. Thus, patients with a mean use of CPAP device $\geq 6.5 \mathrm{~h}$ /day reported an improvement in their condition, while no significant associations between the duration of CPAP use and OSAS type and comorbid conditions. Patients with a daily CPAP use $\geq 6.5 \mathrm{~h}$ had a significantly higher AHI as compared to those with daily CPAP use of $<6 \mathrm{~h}$. With regard to BMI, those with a higher BMI were more likely to have REM-related OSAS $(P=0.002)$ and were more likely to be female $(P=0.000)$, while no other significant differences could be found between the groups.

\section{Discussion}

In this study, we assessed the adherence rates to CPAP therapy in patients with positional or REM related OSAS. Many previous studies have also looked into the same subject, either through objective assessments by device-based measurements or using patient questionnaires, as in our study. ${ }^{[5,7,9-12]}$ In line with one of our previous work, positional OSAS was more common among male patients with more severe OSAS, while BMI was lower ${ }^{[13]}$ More than half of the patients participating our study $(53.1 \%)$ did not receive the physician-recommended CPAP therapy due to a number of reasons. In our study, a minimum of $4 \mathrm{~h}$ of CPAP usage which was advised in the literature was provided in both groups. Patients with positional OSAS reported $6.9 \pm 1.7 \mathrm{~h}$ of CPAP usage, and patients with REM-dependent OSAS reported duration of $6.3 \pm 2.0 \mathrm{~h}$. Furthermore, despite the differences in clinical sleep patterns, patients with positional or REM-related OSAS did not differ significantly with regard to adherence to CPAP therapy.

Previously, ethnicity and sociocultural level have been reported to affect the adherence rates. For instance, in one study, people of European ancestry and individuals with higher sociocultural levels were found to have better compliance to treatment. Similarly, Afro-Americans were reported to have lower adherence to CPAP devices as compared to white Americans ${ }^{[14,15]}$ Our country is a developing country with a relatively low socioeconomic status of the general population. Therefore, it may not be surprising to observe a low adherence to CPAP therapy. In this regard, patients either with REM-related OSAS or positional OSAS were found to have similar rates of CPAP use ( $45 \%$ and $47.3 \%$, respectively), with no significant differences.

The definition of good compliance to CPAP therapy shows some variability between studies, with some considering minimum $4 \mathrm{~h}$ of CPAP use for at least 5 days/week a good adherence, and others considering daily CPAP use of at least $6 \mathrm{~h}$ a good adherence. ${ }^{[7,16-18]}$ In the current study, the cut-off value (hours/night) after which patients reported improvement was minimum $6.5 \mathrm{~h}$ of daily CPAP use (sensitivity 0.64, specificity 0.78). Budhiraja et al. observed no effect of gender on adherence to CPAP, while Villar et al. found that the female gender was associated with better treatment compliance. ${ }^{[19,20]}$ In our study, there were no gender differences with regard to CPAP use at a cut-off value of $6.5 \mathrm{~h}$. Although the proposed ideal minimum duration is between $4 \mathrm{~h}$ and $6 \mathrm{~h}$, studies have reported better outcomes with any duration of use as compared to no use, with benefits increasing with increasing duration of use. ${ }^{[6]}$

BaHammam et al. ${ }^{[21]}$ showed that the adherence rates to treatment declined with increasing duration of CPAP use, particularly after 10 months, at which time the proportion of those with "good adherence" was $33 \%$. In our study, the mean duration of CPAP use was 30 months, with good adherence in the majority of those utilizing the device. However, this did not lead to a significant difference between patient groups. 
Uzer, et al.: Compliance to CPAP in OSAS

\begin{tabular}{lcc}
\hline Table 2: Comparison of obstructive sleep apnoea syndrome subtypes & \multicolumn{1}{c}{ Positional } \\
\hline & REM-related & $56.1 \pm 11.6$ \\
\hline Age (years), mean \pm SD & $57.9 \pm 10.3$ & $30.7 \pm 5.0$ \\
BMI, mean \pm SD & $34.0 \pm 5.7$ & $23.6 \pm 14.7$ \\
AHI, mean \pm SD & $18.9 \pm 8.8$ & 0.000 \\
Sex, $n$ (\%) & & 0.018 \\
Male & $23(38.3)$ & $164(72.6)$ \\
Female & $37(61.7)$ & $62(27.4)$ \\
Mean duration of use (months) \pm SD & $30.5 \pm 13.0$ & $30.6 \pm 18.2$ \\
Mean number of nights with CPAP use (weekly) \pm SD & $6.0 \pm 1.8$ & $6.1 \pm 1.6$ \\
Mean number of hours with CPAP use (per night) \pm SD & $6.3 \pm 2.0$ & $6.9 \pm 1.7$ \\
Improved?, $n$ (\%) & & 0.000 \\
Yes & $23(92)$ & $94(87.9)$ \\
No change & $2(8)$ & $13(12.1)$ \\
Current CPAP use, $n(\%)$ & & 0.979 \\
Yes & $27(45)$ & 0.113 \\
No & $33(55)$ & $107(47.3)$ \\
Reason (s) for not using CPAP, $n(\%)$ & & $119(52.7)$ \\
Unwillingness & $17(51.5)$ & 0.735 \\
Not reimbursed & $7(21.2)$ & 0.746 \\
Uncomfortable & $6(18.1)$ & $56(47.0)$ \\
Other & $3(9.0)$ & $24(20.1)$ \\
\hline
\end{tabular}

BMI: Body mass index, AHI: Apnea-hypopnea index, SD: Standard deviation, CPAP: Continuous positive airway pressure, REM: Rapid eye movement

Studies examining the relationship between OSAS severity and adherence to CPAP reported controversial results. Some studies found a weak correlation between severity of OSAS and compliance to CPAP therapy. Engleman et al. ${ }^{[22]}$ found no correlations between disease severity based on $\mathrm{AHI}$ and patient adherence to therapy, while Wild et al. ${ }^{[23]}$ and Gagnadoux et al. ${ }^{[24]}$ observed a significant increase in treatment adherence rates with increasing severity of apnea. ${ }^{[25]}$ Despite these studies, many clinicians hold the view that patients with higher AHI exhibit better treatment compliance. ${ }^{[26]}$ In our study, although positional OSAS patients had significantly higher AHI, the two groups were comparable in this respect.

Initial studies on adherence to CPAP therapy were mostly based on the data obtained from patient diaries or telephone interviews, as in our study. ${ }^{[1,12]}$ Subsequent studies have shown that patient-reported outcomes are overestimated as compared to objective measurements. ${ }^{[22,27]}$ In this study, the data were acquired through telephone interviews, bringing in the same potential problem mentioned above. However, to the best of our knowledge, this is the first study to compare CPAP adherence rates in two different sleep disorders.

Excessive weight and alcohol use are also known to affect adherence to CPAP therapy. OSAS patients losing weight have been reported to require reduced treatment pressures and vice versa. On the other hand, similar to our observations, some other authors observed no association between the BMI and adherence to CPAP. In a prospective study from China involving 112 patients, no associations of this type have been found. ${ }^{[28]}$

Several limitations of our study should be mentioned. These include the subjective nature of the data, inability to contact or follow some patients, and low number of REM-related OSAS patients.

In conclusion, the results of the present study demonstrate that a significant percentage of patients do not regularly use their CPAP device for various reasons. In this study, a significant proportion of the patients using CPAP devices think subjectively that they have adapted well to the device and their disease is cured. CPAP compliance is not different between two different clinical sleep disorders although patients with positional sleep apnea recorded higher mean AHI scores. Further prospective studies involving more homogeneous patient groups are indicated.

\section{Acknowledgments}

As authors of this study, we are grateful to the Turkish Society of Respiratory Research for their support with the statistical analysis.

\section{Financial support and sponsorship}

Nil.

\section{Conflicts of interest}

There are no conflicts of interest.

\section{RefEREnCES}

1. Epstein LJ, Kristo D, Strollo PJ Jr., Friedman N, Malhotra A, Patil SP, et al. Clinical guideline for the evaluation, management and long-term care of obstructive sleep apnea in adults. J Clin Sleep Med 2009;5:263-76.

2. Fanfulla F, Grassi M, Taurino AE, D'Artavilla Lupo N, Trentin R. The relationship of daytime hypoxemia and nocturnal hypoxia in obstructive sleep apnea syndrome. Sleep 2008;31:249-55.

3. Demir A, Ursavaş A, Tana Aslan A, Gulbay B, Ciftci B, Cuhadaroğlu $\mathrm{C}$, et al. The report of Turkish thoracic society on the diagnosis and 
treatment of obstructive sleep apnea syndromes. Turk Thorac J. 2012;13 (Suppl 1):1-73.

4. Alves C, Caminha JM, da Silva AM, Mendonça D. Compliance to continuous positive airway pressure therapy in a group of Portuguese patients with obstructive sleep apnea syndrome. Sleep Breath 2012;16:555-62.

5. Weaver TE, Sawyer AM. Adherence to continuous positive airway pressure treatment for obstructive sleep apnoea: Implications for future interventions. Indian J Med Res 2010;131:245-58.

6. Weaver TE, Grunstein RR. Adherence to continuous positive airway pressure therapy: The challenge to effective treatment. Proc Am Thorac Soc 2008;5:173-8.

7. Rotenberg BW, Murariu D, Pang KP. Trends in CPAP adherence over twenty years of data collection: A flattened curve. J Otolaryngol Head Neck Surg 2016;45:43-52.

8. Berry RB, Budhiraja R, Gottlieb DJ, Gozal D, Iber C, Kapur VK, et al. Rules for scoring respiratory events in sleep: Update of the 2007 AASM manual for the scoring of sleep and associated events. Deliberations of the Sleep Apnea Definitions Task Force of the American Academy of Sleep Medicine. J Clin Sleep Med 2012;8:597-619.

9. Roecklein KA, Schumacher JA, Gabriele JM, Fagan C, Baran AS, Richert AC. Personalized feedback to improve CPAP adherence in obstructive sleep apnea. Behav Sleep Med 2010;8:105-12.

10. To KW, Chan WC, Choo KL, Lam WK, Wong KK, Hui DS. A randomized cross-over study of auto-continuous positive airway pressure versus fixed-continuous positive airway pressure in patients with obstructive sleep apnoea. Respirology 2008;13:79-86.

11. Krieger J. Long-term compliance with nasal continuous positive airway pressure (CPAP) in obstructive sleep apnea patients and nonapneic snorers. Sleep 1992;15:6.

12. Sanders MH, Gruendl CA, Rogers RM. Patient compliance with nasal CPAP therapy for sleep apnea. Chest 1986;90:330-3.

13. Uzer F, Toptaş AB, Okur U, Bozkurt S, Dogrul E, Turhan M, et al. Comparison of positional ad rapid eye movement - dependent sleep apnea syndromes. Ann Thorac Med 2018;13:42-7.

14. Joo MJ, Herdegen JJ. Sleep apnea in an urban public hospital: Assessment of severity and treatment adherence. J Clin Sleep Med 2007;3:285-8

15. Campbell A, Neill A, Lory R. Ethnicity and socioeconomic status predict initial continuous positive airway pressure compliance in New Zealand adults with obstructive sleep apnoea. Intern Med J 2012;42:95-101.

16. Kribbs NB, Pack AI, Kline LR, Smith PL, Schwartz AR, Schubert NM, et al. Objective measurement of patterns of nasal CPAP use by patients with obstructive sleep apnea. Am Rev Respir Dis 1993;147:887-95.

17. Schwab RJ, Badr SM, Epstein LJ, Gay PC, Gozal D, Kohler M, et al. An official American Thoracic Society statement: Continuous positive airway pressure adherence tracking systems. The optimal monitoring strategies and outcome measures in adults. Am J Respir Crit Care Med 2013;188:613-20.

18. Collard P, Pieters T, Aubert G, Delguste P, Rodenstein DO. Compliance with nasal CPAP in obstructive sleep apnea patients. Sleep Med Rev 1997; 1:33-44.

19. Budhiraja R, Parthasarathy S, Drake CL, Roth T, Sharief I, Budhiraja P, et al. Early CPAP use identifies subsequent adherence to CPAP therapy. Sleep 2007;30:320-4.

20. Villar I, Izuel M, Carrizo S, Vicente E, Marin JM. Medication adherence and persistence in severe obstructive sleep apnea. Sleep 2009;32:623-8.

21. BaHammam AS, Alassiri SS, Al-Adab AH, Alsadhan IM, Altheyab AM, Alrayes $\mathrm{AH}$, et al. Long-term compliance with continuous positive airway pressure in Saudi patients with obstructive sleep apnea A prospective cohort study. Saudi Med J 2015;36:911-9.

22. Engleman HM, Martin SE, Douglas NJ. Compliance with CPAP therapy in patients with the sleep apnoea/hypopnoea syndrome. Thorax 1994;49:263-6.

23. Wild MR, Engleman HM, Douglas NJ, Espie CA. Can psychological factors help us to determine adherence to CPAP? A prospective study. Eur Respir J 2004;24:461-5.

24. Gagnadoux F, Le Vaillant M, Goupil F, Pigeanne T, Chollet S, Masson P, et al. Influence of marital status and employment status on long-term adherence with continuous positive airway pressure in sleep apnea patients. PLoS One 2011;6:95-101.

25. Yetkin O, Kunter E, Gunen H. CPAP compliance in patients with obstructive sleep apnea syndrome. Sleep Breath 2008;12:365-7.

26. Sawyer AM, Gooneratne NS, Marcus CL, Ofer D, Richards KC, Weaver TE. A systematic review of CPAP adherence across age groups: Clinical and empiric insights for developing CPAP adherence interventions. Sleep Med Rev 2011;15:343-56.

27. Rauscher H, Formanek D, Popp W, Zwick H. Self-reported vs measured compliance with nasal CPAP for obstructive sleep apnea. Chest 1993;103:1675-80.

28. Hui DS, Choy DK, Li TS, Ko FW, Wong KK, Chan JK, et al. Determinants of continuous positive airway pressure compliance in a group of Chinese patients with obstructive sleep apnea. Chest 2001;120:170-6 